\title{
The Impact of Delivering Mindfulness-Based Programmes in Schools: A Qualitative Study
}

\author{
Katie R. Norton $\left.{ }^{1}\right)^{1}$ Gemma M. Griffith ${ }^{1}$
}

Published online: 3 July 2020

(c) The Author(s) 2020

\begin{abstract}
There has been an increased interest in the delivery of Mindfulness-Based Programmes (MBPs) in schools yet little is known about how people who deliver MBPs in schools carry out and experience implementation. In this qualitative study, we aimed to examine the experiences of school staff who have a personal mindfulness practice, and who also deliver MBPs to their students. We recruited eight school staff (age range 34-64) who taught students mindfulness, and carried out semi-structured interviews focusing on investigating their positive and negative experiences of delivering mindfulness in schools, how practicing and delivering mindfulness affected their work-life, and their experiences of implementing school-based MBPs. School staff reported that delivering MBPs deepened their own mindfulness practice. The practice enabled them to feel better attuned to others, increased compassion for both themselves and students, helped their emotional regulation, and enhanced resilience to stress. Unexpectedly, half of the participants reported making changes to their work roles and several explicitly linked these changes to the increased self-compassion developed through mindfulness practice. They reported enjoying teaching school students MBPs (and noted that some students embraced mindfulness, and some were reluctant to engage) and sometimes found driving the implementation of MBPs in their school challenging. There appear to be numerous benefits of a personal mindfulness practice for school staff and delivering school-based MBPs can increase feelings of personal accomplishment. Future research is needed into whether MBPs can improve student-teacher relationships, and how some schools have successfully implemented MBPs.
\end{abstract}

Keywords Mindfulness $\cdot$ Schools $\cdot$ Teachers $\cdot$ Qualitative $\cdot$ Implementation

\section{Highlights}

- School staff found mindfulness practice increased compassion for themselves and students.

- Half of the participants (four) had recently resigned or reduced their school hours.

- Participants enjoyed teaching mindfulness though not all students engaged with it.

- Staff found that introducing mindfulness to staff first helped to implement student MBPs.

There is increased interest in bringing mindfulness into education in the current context of the decline in young people's mental health, coupled with increases in teachers' occupational stress and burnout (Roeser et al. 2013; Weare 2013). Relatively few schools are currently offering

Katie R. Norton

katie.norton@bangor.ac.uk

1 Centre for Mindfulness Research and Practice, School of Psychology, Brigantia Building, Bangor University, Bangor, Gwynedd LL57 2AS, UK formalised provision of Mindfulness-Based Programmes (MBPs) to students through the curriculum, where school staff have both taken an MBP and are then further trained to teach mindfulness to their students (Wilde et al. 2019), although this number appears to be increasing. There is evidence to suggest that participating in mindfulness interventions decreases negative affect and increases positive affect for young people, and also reduces symptoms of depression, anxiety, stress, and burnout in school staff (Hwang et al. 2017; Weare 2014), therefore offering MBPs in schools may be a positive intervention for staff and students alike. 
There are more than 2500 teachers in the UK and Ireland trained to teach MBPs to students, across approximately 2000 schools (Mindfulness All-Party Parliamentary Group [MAPPG] 2015; Mindfulness in Schools Project [MiSP], personal communication, 10 May, 2018). Recent recommendations to train more teachers to deliver mindfulness to their students are welcome (MAPPG 2015), yet it seems prudent to first examine the experiences of school staff who have implemented MBPs in their classrooms before rolling out larger-scale implementation in schools. As is common in MBP research, most studies on mindfulness in schools have focused on stage I and II (which focus on intervention generation, refinement, and efficacy) of the National Institutes of Health (NIH) stage model (Dimidjian and Segal 2015; Onken et al. 2014). As schools are already offering MBP programmes for their staff and students, however, it is important to balance the development research with research on how MBPs are implemented in the community (i.e. NIH Stages IV and V). Dimidjian and Segal (2015) identified the dearth of Stage IV and $\mathrm{V}$ studies in MBP research, with under $2 \%$ of the MBP studies they reviewed falling into these two categories, and called for more MBP research based on implementation and dissemination. To date, although there is some putative evidence that MBPs may contribute to teacher and student wellbeing, little is known about how MBPs 'in the real world' are experienced by the school staff who implement them. This knowledge may help with the future implementations of MBPs in school settings.

A preliminary literature search was carried out in April 2019 through PsycINFO and Google Scholar using the search terms: 'mindfulness', 'school', 'staff' and 'delivery', searching for articles in the English language. To date, while there have been a range of studies on the impact of taking a mindfulness intervention on school staff member's psychological functioning, the literature search revealed no research had yet been published on how staff experience both practising mindfulness and delivering MBPs to student groups.

MBPs originated in the late 1970 s and usually take the form of a sequence of eight weekly group sessions that include movement and meditation practices, and psychoeducational information about stress and reactivity (Crane et al. 2017; Kabat-Zinn 1996). MBPs provide participants with the opportunity to develop experiential awareness through formal 'practices' such as awareness of breath or mindful movement, where participants train in bringing back their wandering attention to a particular focus, while cultivating a non-judgemental stance towards their experience. Participants are encouraged to sustain their attention on internal experiences and enquire into these, as well as participate in a collective enquiry into universal human vulnerability (the distress that is a feature of human experience, often compounded by unhelpful, habitual, reactive patterns of the brain) (Crane et al. 2017). This encourages participants to develop a new relationship to their experience, by seeing their own thoughts, behaviours, and emotional and physical states from a more 'witnessing' stance, within a wider space of awareness.

Schools may be one of the best places to offer mindfulness interventions to young people, and school staff may be the best placed to deliver them (Zenner et al. 2014). Preliminary systematic reviews and meta-analyses on MBPs have indicated there are a range of benefits for young people (Felver and Jennings 2016; McKeering and Hwang 2019). These include the alleviation of psychopathological symptoms such as depression and anxiety (Burke 2010; Zoogman et al. 2014), and increased positive affect in areas such as resilience and empathy (Zenner et al. 2014). Several studies have also reported that skills taught through MBPs enhance the attentional capacity and neuroplasticity of students (Davidson et al. 2012; Zenner et al. 2014). In terms of delivery of MBPs, trained school staff may be more effective than outside trainers, as they are likely to have an existing rapport with students, and consolidated classroom management skills (Burnett 2009). School staff may also have a more nuanced understanding of child development and what is appropriate in the classroom environment than external trainers (Jennings 2016).

The research field on the outcomes of MBPs on school staff is also small, yet points to some promising positive outcomes (Weare 2014). Most studies have been quantitative to date: eight controlled trials have assessed the impact of MBPs for teachers (Benn et al. 2012; Beshai et al. 2016; Flook et al. 2013; Frank et al. 2015; Kemeny et al. 2012; Roeser et al. 2013; Rupprecht et al. 2017; Taylor et al. 2016). MBPs had statistically significant effects on improving aspects of psychological functioning, as symptoms of depression, anxiety and stress substantially decreased (Roeser et al. 2013; Rupprecht et al. 2017), and there were significant increases in self-compassion (Benn et al. 2012; Beshai et al. 2016). Other reported benefits included: improved emotional regulation and empathetic concern in teachers (Benn et al. 2012; Taylor et al. 2016); large reductions in burnout symptoms (Flook et al. 2013; Roeser et al. 2013); improvements in self-reported efficacy (Frank et al. 2015; Rupprecht et al. 2017); and significant improvements in independent ratings of a teacher's classroom behaviour (Kemeny et al. 2012). A range of objective and subjective measures were used when reporting these putative benefits.

To our knowledge, just one small qualitative study (Napoli 2004) has been conducted on the impact of a mindfulness intervention delivered to primary teachers $(N=3)$ and their students. Teachers reported benefits from the course, and described using a wider awareness to 
recognise difficult situations or emotions: "I'm trying to do two and three things at one time and so... I find myself just stopping, regrouping, taking a breath and then going back" (p. 37-8). However, most of the research done on the impact of MBPs for teachers has been quantitative. While this is useful for generating early, generalised findings about outcomes for teachers and promoting future interventions, there is still much about the effects of mindfulness practice on a member of school staff's professional life that is unknown. One review of this emerging field of research called for more 'phenomena-finding' methodologies to be used (Roeser et al. 2012).

Meiklejohn et al. (2012) described three ways in which mindfulness can brought into the school classroom: (1) indirectly - where the teacher's own mindfulness practice and embodiment of mindful attitudes and behaviours may be implicitly conveyed to their students; (2) directlywhere students are explicitly taught mindfulness skills and practices through MBPs; or (3) a combination of both the direct and indirect approaches. All of the aforementioned studies are concerned with the indirect approach. A few papers have commented on issues around implementing MBPs in schools, either through discussing challenges when implementing a research intervention or from the point of view of school staff who were trained to deliver it (Desmond and Hanich 2010; Joyce et al. 2010), while Wilde et al. (2019) explored the challenges and facilitators to instigating school-based MBPs. Apart from this, and anecdotal evidence in teaching guides written by mindfulness teachers who have worked in schools delivering MBPs to young people (Hawkins 2017; Jennings 2015), very little is known about how school staff may find the direct approach of delivering mindfulness to their students.

The aim of this study is to capture the experience of school staff who deliver mindfulness to students, using a combination of the 'direct' (explicit delivery of MBPs) and 'indirect' (where teacher's own practice may be implicitly conveyed) approaches (Meiklejohn et al. 2012). In order to unpack this experience, the study focuses on school staff's perspectives on the positive and negative aspects of delivering MBPs in the workplace; how both practising and delivering mindfulness has affected their work life; the obstacles and facilitators to delivering MBPs in schools; and how school staff can best be supported when delivering MBPs.

\section{Methods}

\section{Participants}

Participants were school staff trained in the '.b' programme, authored by the UK-based Mindfulness in Schools Project (MiSP). The '.b' curriculum (short for 'Stop, Breathe and
Be') is composed of 9-10 mindfulness sessions aimed at 11-18 year olds. This curriculum was chosen as it includes the 'essential elements' of MBPs as specified by Crane et al. (2017) as well as being appropriately adapted for schools, by having shortened components and interactive, lively activities relevant to young people (Kuyken et al. 2013). One of the key practices taught through this curriculum is a '.b': a 'breathing space', where students are reminded to pause, feel grounded in their bodies, become aware of their breathing and take note of their experience at that particular moment.

To be included in the study, participants (a) were working in a school in the UK or Ireland, (b) had trained to teach the '.b' training programme and (c) had taught more than two sessions of mindfulness to students and intended to teach more in the future. The last criterion was set deliberately low to represent a range of experiences, including staff who had minimal experience of teaching.b sessions in their schools. The second criterion also ensured that participants practised mindfulness, as in order to teach '. b' individuals must take a recognised 8-week MBP, hold a daily formal mindfulness practice for at least six months, and commit to continued personal mindfulness practice (MiSP 2017).

Eight participants were recruited, five females and three males, who were between 34 and 64 years old $(M=51.3$ years) and had spent between 10 and 33 years working with young people $(\mathrm{M}=24$ years). Half of the participants worked in state schools, the other half in private schools; seven were trained teachers and one was a full-time school counsellor (qualified teacher status was not set as part of the inclusion criteria in order to represent all those who might deliver MBPs in a school). All participants had initiated or co-initiated the delivery of MBPs to students in their schools. There was a range of experience in teaching mindfulness to students: one participant had only one academic year's experience and had taught two .b courses, while another participant had taught over thirty .b courses. See Table 1 for individual demographic information.

\section{Procedure}

In order to make the sample as homogenous as possible (Braun and Clarke 2013), recruitment was targeted at school staff trained in the '.b' curriculum created by MiSP, rather than a range of school-based MBPs. The first author carried out modified purposive sampling by posting the recruitment advert to three email groups listings and two online forums of '.b' trained teachers. Willing participants contacted the first author and signed a consent form, then the researcher gathered their background information (see Table 1) and later conducted a 50-65 min interview via telephone, video call, or in person. 
Table 1 Demographic characteristics of participants

\begin{tabular}{lcccccccc}
\hline Name & Bill & George & Beth & Rich & Patricia & Pippa & Grace & Tamsin \\
\hline Gender & M & M & F & M & F & F & F & F \\
Age & 58 & 46 & 55 & 53 & 49 & 34 & 51 & 64 \\
Years in education & 30 & 24 & 32 & 20 & 15 & 10 & 28 & 33 \\
MBP courses taught to students & 13 & 7 & 6 & $30-40$ & 4 & 4 & 3 & 2 \\
\hline
\end{tabular}

Table 2 Interview schedule

Interview questions

1. How did you come to train in delivering mindfulness to students? 2. What has been, if anything, positive or inspiring about delivering these sessions for you, so far?

3 . What has been, if anything, challenging or negative about delivering these sessions for you, so far?

4. Is there anything else that you'd like to comment on with regards to teaching MBPs?

Implementation of MBPs

5. Are there any barriers or obstacles to delivering mindfulness that you've met? If so, what?

6 . Is there anything that you feel has helped you to deliver mindfulness to students? If so, what?

\section{Professional Life}

7. Has practising/teaching mindfulness affected your relationships with students (in and/or out of sessions) differently? If so, how?

8. Has practising/teaching mindfulness affected your relationships with other members of the school's community (e.g. staff/parents)? If so, how?

9. Has practising/teaching mindfulness changed your perception of your occupational role? If so, how?

\section{Impact on you}

10. How would you describe your own mindfulness practice? (after Q1)

11. Has practising mindfulness made a difference to how you view yourself in difficult times? If so, how?

12. Has practising mindfulness impacted on your sense of work-life balance? If so, how?

13. Do you feel like practising or teaching mindfulness to students has affected your life outside school in any other way?

A semi-structured interview schedule was created for the purpose of this research (see Table 2). After the interview, and once the themes were written, the lead researcher carried out a 'member check' by emailing the results section to participants and inviting feedback, in order to check the validity of the researchers' theme interpretation (Elliott et al. 1999).

\section{Data Analysis}

The Journal Article Reporting Standards for Qualitative Research (JARS-Qual; Levitt et al. 2018) was adhered to throughout the data collection and analysis, which outlines key standards for qualitative researchers to adhere to. Inductive thematic analysis was chosen because it is a flexible, accessible method of analysing data and because little is known about school staff's experience of delivering MBPs to their students (Braun and Clarke 2006, 2013). Therefore, an inductive method-in which the researchers generate the analysis from the data 'bottom up' and which it is not shaped by extant theory-was deemed the most suitable (Braun and Clarke 2013).

The authors followed the six phases of thematic analysis, as described by Braun and Clarke (2006). The lead researcher carried out the first phase of the analysis, which involves becoming familiar with the data. This was achieved by reading and re-reading each of the eight interview transcripts and making notes on initial thoughts about the data and potential codes. The second phase involved generating initial codes across the body of data by identifying and collating particular data extracts which seem to speak to a particular feature or interesting aspect and labelling them. Third, the lead researcher then started to group the initial codes for each interview into broader themes by searching for wider patterns of meaning across the data set. The fourth stage involved reviewing and refining these themes: Both authors discussed and sketched out a broader thematic framework for meaning and patterns, and then the lead researcher drew up theme tables for each major theme. This also involved collating themes and subthemes that were similar and reducing initial codes and themes that were not consistent with the broader framework. Fifth, the lead researcher defined and named themes by further refining the specifics of each one in order that each theme could tell a story succinctly but also fit into the wider narrative of the data. In the last stage of producing a report, the lead researcher wrote up themes with the aim of evidencing themes with data extracts and also explaining how each data extract captured an aspect of the theme as well.

The plausibility and coherence of the lead author's interpretation was investigated and developed by using a number of recommended checks throughout the analysis (Braun and Clarke 2013; Levitt et al. 2018). These checks included: keeping a reflective diary; re-reading the transcripts after an initial draft of data themes; carrying out a 'member check' with all participants, to which four responded and reported that themes were consistent with their experience. Additionally, the data were triangulated with the second author, who read one original transcript and worked alongside the first author to check the different 
stages of analysis for theme interpretation, and in the write up of emergent themes.

\section{Results}

When quoting interview data, the following conventions have been used:

[...] Where text has been removed

(...) A pause

[text] Where text has been inserted to clarify meaning.

Four themes and ten sub-themes were developed from the data. See Table 3 for the title of themes and subthemes.

\section{Relationships in the School}

Participants spent much time discussing the mainly positive impact that practising and delivering mindfulness had on relationships with others in the school, particularly with their students. Many said they had a "better rapport" with students and fewer discipline problems in the classroom.

\section{Increased presence and openness with students}

Over half of the school staff spoke of how the quality of their attention had improved in interactions with students; they felt more present and alive to their students by paying attention to non-verbal communication. Beth noted that:

I find them more interesting as individuals, I'm more curious about them, and I spend more time noticing things about them-and how they're responding and why they're responding in that way [...] I used to just be-I drifted into becoming a little bit more "this is what it is, get on with it".

Beth's enhanced attention allowed her to know and recognise each student on a more personal level, leading to students feeling more understood and "seen", and cultivating more openness in her relationships with them.

Several participants expressed how their willingness to be more authentic and honest (as a result of an increased awareness of and compassion for their own difficulties) led to relationships of greater trust with students. Pippa discussed the impact of sharing her own challenges around focussing on the breath with students:

That kind of: "Look this is something that's hard for everyone to do, but everyone says it does help..." [...] So by just being really real, and not putting yourself out as an expert in anything, it [...] makes the students feel safer.

She emphasised how being open about her experiences reduced traditional hierarchical teacher/student roles, and when she shared her annoyance at losing focus, it "Kind of disarmed them and made them realise that maybe I was on their side". George also described several occasions where, because of his willingness to apologise for his role in a classroom conflict with a student: "I could notice in their body, they became softer. It's like that defensive attack mode had kind of reduced a bit and [...] it was safe for them, then, to maybe acknowledge their own part". Pippa and George discussed how their own openness to difficulties and mistakes in turn allowed students to do the same. Both used language that suggested how some students may perceive student-teacher relationships as a battleground ("Disarm"/"Attack"), yet felt that their increased willingness to be 'human' in front of students enabled a climate of increased safety and trust in the classroom.

\section{Understanding challenging student behaviour}

Over half the school staff felt that their understanding of challenging student behaviour had changed as a result of cultivating acceptance through mindfulness practice and
Table 3 Superordinate and subordinate themes

\begin{tabular}{ll}
\hline Superordinate themes & Subordinate themes \\
\hline Relationships in the school & - Increased presence and openness with students \\
& - Understanding challenging student behaviour \\
Delivering the MBP to students & - Students' responses to MBPs \\
& - MBPs offer a key life skill \\
How mindfulness impacts on work-life & - Mindfulness enhances work-life \\
& - Increased resilience \\
& - Awareness of reactivity \\
Getting MBPs onto the school curriculum: & - Sreater self-kindness \\
Implementation issues & - Fit between MBPs and current educational \\
& approaches \\
\hline
\end{tabular}


delivery. One stated that he had "Much less discipline problems" (Bill) and others explained that their increased perception of students' "Emotional lives and how key that is to behaviour" (Grace) had led to understanding that difficult behaviour could be masking difficult emotions. Rich explained:

I would be more compassionate, more understanding [...] more aware of what they were bringing to the lesson. And just seeing them for what they are-what, what the problem was rather than seeing it as a deliberate affront to me; you know, me-'Rich'.

The recognition that students' actions were an expression of past experience and their current developmental stage rather than anything to do with him personally ("Me - 'Rich"), led him to a wider, compassionate perspective where universal human vulnerability, and the personhood of the student, was recognised. These new perspectives, alongside participant reports that they experienced less emotional reactivity (see sub-theme 'Awareness of reactivity'), led to many of the staff experiencing calmer learning environments with less conflict.

\section{Delivering the MBP to Students}

School staff reported that the majority of young people found mindfulness sessions enjoyable and useful. When students did not respond well, some participants found it challenging to maintain equilibrium. Many felt that teaching the.$b$ curriculum gave them more job satisfaction and fulfilment.

\section{Students' responses to MBP courses}

The majority of staff described how students enjoyed and engaged well with the .b curriculum. Most participants described particular situations where students had told them about their spontaneous uses of mindfulness practicessuch as during written and oral exams (Bill and Patricia); getting to sleep (Tamsin); overcoming difficulties like losing at sport, family conflicts and low mood (Grace and Rich) - and how this led to a sense of fulfilment in their teaching role.

Half of the participants spoke of how some students were not engaged in the .b sessions or interested in doing "home practice" (brief meditations given to pupils to practice at home). Rich and Bill explained how sometimes it was "Quite hard work" and "Difficult" teaching students who were not motivated (which Bill had experienced particularly when starting to deliver .b). Grace also expressed distress when encountering 'Children who'll be fiddling or who'll be day dreaming" during practices. Several noted that the majority of their students do not do the suggested home practice after sessions, and Rich described how he experienced this:

There's the kind of "Oh but you're missing out!" [..] a kind of little bit of sadness in that and that's quite hard. Especially with the [...] young people whoyou just think "Oh, this would be so good for you..."

Alongside Grace, he described a kind of wistfulness at the thought of students not accessing approaches that could help them with their school lives and well-being.

\section{MBPs offer a key life skill}

Almost all participants spontaneously reflected on the wider role that the delivery of mindfulness to students had to play in schools. Many described delivering MBPs as the most "Worthy" (Grace) teaching they had done, despite sometimes encountering student disengagement. Several echoed Tamsin's statement of "This is what I came into education to do" and Bill and Beth said that their mindfulness lessons were more "Enjoyable" to teach than their normal subject. Rich explained how he found teaching mindfulness was different to subject teaching:

Teaching them skills $[\ldots]$ just to pass an exam [...] almost like I was part of the problem, you know, it was causing them stress. Here I'm able to help them and possibly alleviate some of that stress and, you know, teach them ways in which they're able to cope with-cope with what life has to bring.

Some participants noted that the mode of delivering mindfulness contrasted strongly with schools' expectations of student progress and attainment:

I can't leave a science class with some people not having got it. But I can leave a mindfulness class just knowing I just have to have planted a seed; I don't have to have solved the problem for them. (Beth)

Beth explained here that as the impetus in MBPs is on introducing ideas and practices, there is a release from the need to achieve particular outcomes from students. As Rich says, the skills presented in mindfulness sessions may not be appropriate for all students: "They will come to it when they're ready, if they are ever... it's got its own time and its own cycle". He and Beth both used horticultural metaphors ("Seed" and "Cycle") to describe a sense of non-striving: of letting students develop organically, at their own pace. 


\section{How Mindfulness Impacts on Work-Life}

Participants spoke about how teaching the .b curriculum helped to deepen their own personal mindfulness practice. This deeper mindfulness practice allowed participants to better manage the stressful and difficult parts of their job. Many particularly spoke of their development of selfkindness as an important part of this process.

\section{Mindfulness enhances school-life}

Half the participants said that the combination of teaching.b and the subsequent deepening of their personal mindfulness practice had "Transformed" their experience of working in a school. Bill and Beth attributed being "Better" or "More effective" teachers to practising mindfulness, because they felt more attuned to students and able to manage difficult situations. Others discussed how their whole perception of school-life had changed: Both Tamsin ("the clarity of my job [...] mindfulness has just bought that into focus really") and Grace ("my relationship with myself, how I see others, my pupils, erm ...... yeah it just seems to-to colour ... it's like I'm looking through a different lens") used visual metaphors to seemingly explain an enhanced and altered perspective ("Different lens"/“Focus") on their work-life.

Some participants-particularly those who had more recently started learning about mindfulness-also went on to describe how delivering .b sessions had helped them to personally integrate mindfulness into their work lives. Delivering.$b$ reinforced and deepened their understanding of mindfulness ideas, and gave them opportunities to meditate at school. Tamsin and Pippa both appreciated that .b sessions allowed them space for stillness; albeit as Tamsin said, still with "An eye on" what was happening in the classroom. Bill and Pippa also explained how familiarising themselves with and cultivating mindfulness, in order to teach it, inevitably deepened their awareness: "I was more aware and I suppose by talking the talk it makes you do it! [...] it helped me to become more mindful because I was using it with them, so I was using it more with myself" (Pippa).

Participants described using the '.b' practice when walking around the school (Pippa), in the middle of lessons or assemblies (Bill) or in difficult situations with colleagues or students (Tamsin and Bill). For the majority, delivering sessions enriched their understanding and foregrounded their practice into daily routines, so there was a symbiotic relationship between delivering mindfulness sessions and integrating their personal mindfulness practice into their work lives.

\section{Increased resilience}

Almost all school staff reported that the cultivation of a personal mindfulness practice helped them deal with the pace of work. Participants spoke about school-life as a "Hamster wheel" or "A treadmill" to convey ideas of frantic-ness with little time to rest. Seven participants said that while the pace of school remained the same, by using mindfulness approaches, they were able to create space for themselves within this busyness. Rich explained how in the past he was "Always trying to run to keep ahead of things" but now "It's notice and take pause, and gaps, so you've just still got that intensity but $[\ldots]$ there's spaces in between". Beth described how noticing difficult situations and their effects helped her to recover from difficulties quicker and become more resilient:

Just the sort of noticing [of difficult aspects of the job] helps regulate and keep it so that you can shift from one to the other, in a really, in an easier way-without taking one in to the lesson with you.

Participants used metaphors to give a sense of how-premindfulness practice- they felt almost trapped by feelings of stress ("Caught"/“Entangled"/“Under the skin"), yet now had a sense of a freedom ("Not caught"/“Step away from") in their relationship to the busy workplace. Several noted that this had increased their well-being and felt like a much "Healthier" approach to the workplace.

\section{Awareness of reactivity}

The majority of participants spoke of how they were more "Emotionally literate" (Grace) after deepening their own mindfulness practice. George, for example, reported that when something "Is kicking off in the classroom", he is now more aware of the emotional, physical and cognitive aspects of his experience (e.g., thoughts such as "'Oh it shouldn't be like this'") and thus is less likely to react in his habitual way. Bill also described situations when:

How I'm feeling starts coming into the room [...] And acknowledging that 'yup, I'm just feeling tired that morning'. That's all it means. [..] Just treating it as a thing that I'm feeling and therefore it doesn't have to be the thing that dominates what I do in the classroom.

Bill noted that his emotional state is "Just a thing". By choosing the indefinite article "a" (indicating that the noun is one of many phenomena), he conveyed that the feeling of tiredness is just another aspect of his experience. This contrasts with his pre-mindfulness approach where feeling tired was "The thing": his use of the definite article means that he would have previously overwhelmingly identified with this state. In this way, feeling-states become less singular and more manageable when awareness is bought to them, and as Patricia stated: "It allows those feelings just to 
be $[\ldots]$ without them being threatening". The acknowledgement of moment-to-moment feelings led to participants reporting that their negative emotions could be tolerated rather than feared, thus leading to enhanced emotional regulation.

\section{Greater self-kindness}

All school staff spoke about how mindfulness practice led them to greater self-kindness in the workplace. Most described an active cultivation of more compassionate, understanding approaches towards themselves when experiencing difficult emotions at work: some, for example, asked themselves "How can I be kind to a mind that's angry, or, to a mind that's irritated?" (George), or treated themselves with more kindness when they noticed the "[Be] perfect, don't fail script" (Patricia). Over half of the participants spoke of how they create spaces during the working day for self-care. Bill, for example, spoke about how he changed his normal routine from always attending a weekly event during lunchtime, to instead: "I'm going to my room and get on with what I wanted to do, which was to do a bit of preparation for the afternoon, a bit of marking and actually a bit of mindfulness in fact!"

Although none of the participants were specifically asked about career changes, half of them spoke spontaneously about recent alterations to their career. Two participants had moved from full-time to part-time work in their schools, while two more had recently resigned. The latter two both attributed this decision to the clarity that mindfulness gave, enabling them to see this as an act of self-compassion, instead of struggling with difficult circumstances: "There was a-was a certain sense of: this is being kind to yourself, you don't have to be in this confrontation the whole time" (Tamsin). Mindfulness practice allowed participants to take a step back and clearly see how their work was impacting on them, with a few taking actions to enhance their wellbeing by making changes in their career.

\section{Getting MBPs onto the School Curriculum: Implementation Issues}

Participants were drivers of.$b$ implementation in their school, and this theme explores their experiences of facilitators and obstacles to implementation.

\section{Support from colleagues}

Seven participants identified how support (in terms of investment in training, access to student time, or the curriculum) from members of their Senior Management Team (SMT) had affected their efforts to implement mindfulness. The majority felt that their SMT were supportive, especially members of their SMT who had benefitted from mindfulness practice themselves and consequently supported implementation. Rich taught the .b course to staff groups which included two deputy heads, and as a result: "They've been the real drivers. They've enabled me to get a foot in with senior management, to really push it with staff [..] [and the] student body".

In contrast, several members of staff reported a lack of support from SMT. Patricia described some negativity from her head-teacher-"He's not a big fan of mindfulness, personally; he finds meditation difficult"-and felt this hindered her efforts to implement MBPs. Tamsin also described the lack of enthusiasm from SMT in her school but, due to her status as a pastoral manager, had been able to deliver courses through Personal, Social, Health and Economic Education (PSHEe) lessons. Several others also noted that support from pastoral staff helped in terms of accessing curriculum time (Pippa) and encouraging the teacher's application to train in MiSP (Patricia).

Half the participants discussed how taster sessions or MBP courses for school staff had helped to create a more fertile environment for later introducing MBPs to students. Pippa described how a session for her colleagues helped as:

They realised that you know, it can't be bad [...] the staff themselves were a little under pressure and when we did the mindfulness, it was seen as, as this-this is one thing that you can do to calm yourself down...

Patricia had not had that experience but felt "If there'd been more understanding and perhaps just even a handful of teachers who've experienced the benefits" it would have helped in embedding MBPs. She, like several others, felt that she was the only champion of mindfulness in her organisation and echoed Grace's feeling that "If I leave the school, the .b dies". Their comments suggest a poignancy and sadness around being the only ones to support an aspect of education that they find so significant. Patricia felt as if "sometimes you're fighting a greater tide", a metaphor which conjures up a sense of isolation (others talked of being just "One person" or the "Only teacher" interested in mindfulness) and powerlessness in the face of the wider resistance to or disinterest in MBPs in the school.

Not all staff bodies were interested in mindfulness; five participants described experiencing negativity or disengagement from colleagues around mindfulness, either because they thought "Mindfulness is a fad, and a bit hippy" (Beth), or "They just don't know about it or have picked up negative messages from the news media about it and are more suspicious" (Patricia). For some, this fed into a renewed determination to present the benefits of mindfulness to those they worked with. 


\section{Fit between MBPs and current educational approaches}

Most participants noted that one obstacle to implementation was a sense of discrepancy between the current educational climate and the aims of a mindfulness course. Around half described how they had met resistance to introducing MBPs into the curriculum as it was "Quite a way down the list of priorities" (Rich).

Some participants also noted the tension between the core principles of mindfulness approaches and being expected to "sell" MBPs to schools. Patricia reflected on how being "Aggressive with marketing" seemed like the only way to get support for a new intervention and George also cautioned that:

While there can be a huge amount of well-intentioned enthusiasm, I do think it has to be tempered at times $[\ldots]$ as if mindfulness is going to be the panacea for all ills [...] I think that's a misrepresentation of really the outcomes of mindfulness.

Patricia urged care when schools are introducing mindfulness, noting that a hurried approach might "Dilute its impact" because "There'd be a temptation perhaps to bring people on board who are not ready to teach". Participants were personally invested in MBPs and were very concerned about protecting the integrity of school-based MBP programmes in the future.

\section{Discussion}

This study aimed to explore school staff's experiences of teaching MBPs to students. In particular, it aimed to investigate how they found delivering MBPs; how practice and delivery of mindfulness affected aspects of their work life; and the wider context of what it is like to implement MBPs into the school community. The findings are congruent with previous quantitative studies about the effects of mindfulness practice on school staff (Roeser et al. 2013; Taylor et al. 2016) and reflections from other school-based practitioners and studies on issues around implementation (Jennings 2015; Wilde et al. 2019).

Overall, participants experienced delivering MBPs to students as worthwhile, enjoyable and fulfilling. Staff felt that teaching mindfulness was a resource for "Coping with ... life" and was an antidote to the stress that students may experience in academic settings. Participants reported that student feedback was largely positive, although some students did not practice mindfulness outside of the classroom. There was a contrast between participant's perception of mindfulness as an essential life-skill and some students' lack of willingness to focus on the topic in class or invest time in it outside of school. This raises implementation questions about whether mindfulness practices are developmentally appropriate for young people (Kaiser-Greenland 2015) or if MBPs should be delivered through either conscript or voluntary sessions to students. Participants felt that delivering MBPs helped them integrate their personal practice of mindfulness into their work-lives and some reported a symbiotic relationship between their own practice and the delivery of the .b curriculum. They found it difficult to delineate between the two, as the 'direct' approach of delivery fed into the 'indirect' approach of embodying mindfulness in the classroom (Meiklejohn et al. 2012), and noted that an increasingly mindful approach to their work in schools had many benefits.

Staff reported that mindfulness practice benefitted their work lives: they felt more authentic, compassionate and present with others, and more able to "Step back" or decentre from interpersonal conflict. Some participants attributed this to their increased ability to be vulnerable as a teacher, and noted that this, in turn, led to students being more relaxed and open about their own vulnerabilities. This point is echoed by Himelstein (2015), who notes that one of the most important factors in developing trusting relationships with adolescents is the degree to which adults are authentic and can admit to faults.

Participants found that their mindfulness practice enhanced their pro-social dispositions, which contributed towards experiences of better relationships at work. They noted an increase in acceptance or being able to "Just see [students] for what they are", which led to greater feelings of understanding and compassion towards them. Other studies support these findings: Gold et al. (2010) found that school staff who had completed an MBP reported statistically significant increases of 'acceptance without judgement'; Kemeny et al. (2012) reported that school staff practising mindfulness are more primed for a compassionate response; while Taylor et al. (2016) found that teachers described difficult students with less negative language, seeing them in a 'wider emotional light'. Two studies also reported large increases in teacher's dispositional forgiveness (Benn et al. 2012; Taylor et al. 2016). Most of the school staff also discussed how teaching and practising mindfulness had led to greater kindness towards themselves, and increasing awareness and self-compassion are said to lead to increased compassion for others (McCown et al. 2011; Segal et al. 2013).

Participants reported that delivering and practising mindfulness led to fewer feelings of stress and negativity at work. One aspect of this involved being less emotionally reactive to student's difficult behaviour. This could be linked to participants' increased awareness of emotions and subsequent emotional regulation; a change which is reflected in the wider literature around the benefits of and 
mechanisms behind MBPs (Chambers et al. 2009; Feldman et al. 2010). The enhanced ability to 're-perceive' (Shapiro et al. 2006) or 'decentre' (Segal et al. 2013) from difficult emotions was evidenced in the way school staff spoke of their experience of coping with stressors in school: bringing awareness to their own internal reactivity created some sense of distance (decentring) from the emotions felt, which led to a more considered response. MBPs for staff seem to show strongest promise and intermediary effects in the area of teacher's emotional regulation (Emerson et al. 2017) which is significant as emotional reactivity is associated with increased negative interactions with students, stress and burnout in teachers (Montgomery and Rupp 2005).

In the wider literature on mindfulness in the workplace, concerns have been raised about whether increasing employee resilience (so they can better manage negative work events, for example) 'coincides with passivity, allowing unhealthy patterns to continue unchecked' (Good et al. 2016, p. 132). This is currently an open question in the field, but has not been investigated directly. The finding that four out of the eight participants reduced their hours or resigned was unexpected, and suggests that mindfulness practice did not somehow lead to passivity or the continuation of unhealthy patterns, but indeed the opposite. Two participants explicitly said that their mindfulness practice had led them to reconsider their work situation and the impact it was having on their well-being carefully, framing their decision to resign as an act of selfcompassion. Unfortunately, the two participants who went from full time to part-time work were not asked what lead to this decision during the interviews because this was not an area we originally planned to investigate, so we do not know if the decision to reduce their work hours was linked to their mindfulness practice.

In terms of workforce health and productivity, staff member's increased awareness of the strain a role is placing on them and their subsequent role change may benefit the school in the long-term. Recent research into 'self-endangering work behaviour (SEWB)', where employees engage in depleting activities such as extending their work hours to deal with work-related demands, showed that it increases the chances of health problems, impedes recovery from stress and also leads to more burnout (Dettmers et al. 2016). One participant in our study reported that practising mindfulness helped her to let go of the 'be perfect' script which had previously added to her feelings of deleterious stress; Rupprecht et al. (2017) also discovered that a group of school staff who had taken an MBP reported statistically significant reductions in their work engagement post-intervention, in particular, in the areas of 'willingness to work to exhaustion' and 'striving for less perfection'. For individuals, avoiding SEWB may lessen feelings of stress and could possibly lead to staff reporting fewer burnout symptoms, overall. This phenomenon, of half of the participants in the study choosing to self-care by reducing hours or changing career trajectory (and two explicitly attributing this to their mindfulness practice) is one which is worth exploring further, as it does not support the concern that offering MBPs to employees in the workplace can have unintended harmful impacts on employee passivity (Good et al. 2016). However, it should be noted at this point that due to the small sample size, generalisation is not possible. Additionally, the findings are based upon school educators who teach mindfulness to their students. As they teach mindfulness, they are also more likely to be actively engaged in mindfulness practice than employees who take a one-off MBP, for example. Therefore, these findings may not extend to employees in other workplaces, and must be interpreted tentatively - but are worthy of further investigation to lend some clarity to the current debate.

Participants felt that using mindfulness in both their personal and professional life had enhanced their performance at work. They felt they dealt more effectively with challenging behaviour or prioritised activities which better reflected their own professional needs. This finding is similar to Rupprecht et al. (2017) who noted that despite the MBP-intervention group reporting changes in work engagement, there was also a statistically significant increase in their sense of self-efficacy in the classroom; Emerson et al. (2017) also noted that teachers reported an increased sense of self-efficacy after taking MBPs. Educational staff worldwide report high levels of fatigue and debilitation and the occupation is prone to high attrition rates: in Britain, the number of teachers who leave the profession is higher than the numbers who stay until retirement (Chang 2009). One aspect of burnout that is particularly pertinent for school staff is said to be a feeling of low 'personal accomplishment' (Maslach et al. 2010). If taking and delivering MBPs helps school staff to have a sense of fulfilment, as participants reported in this study, then it's possible that supporting those who wish to practise or train in teaching mindfulness could lead to decreased staff burnout. This would complement other studies that have reported that school staff purely participating in an MBP decreases symptoms of burnout across all dimensions of the Maslach Burnout scale (Roeser et al. 2013), particularly in the dimensions of personal accomplishment and emotional exhaustion (Flook et al. 2013). Participants in this study noted that they can better manage the stress and exhaustion that the teaching profession can bring; again, this is significant as teacher resilience positively correlates with improved student outcomes (Hwang et al. 2017).

The twin findings of school staff reducing SEWB (which may include career 'downsizing' or change) yet also experiencing feelings of greater self-efficacy raise interesting questions for educational employers about the nature of 
the school workforce required for the future. One possible outcome could be that staff who train in mindfulness may require more flexibility or autonomy at work and this may clash with practical issues connected with school administration, such as fixed timetables or meeting targets set by national government. Conversely, however, there is the possibility that staff who practice and are involved with mindfulness training may be more effective in their roles and experience less burnout, which might consequently raise standards and reduce staff turnover.

One of the most frequent implementation issues that participants discussed was support from colleagues and senior leaders. A few participants were senior enough to implement it themselves, but most depended on the support of senior management. Experienced teacher-practitioners have recommended that implementers share the emerging evidence base with senior leaders and create opportunities for them to practice, as 'offering decision-makers a personal experience and practice dispels myths and misconceptions, and directly demonstrates the power of mindfulness' (Willard 2015: p. 9). Burnett (2015) also noted that introducing mindfulness to staff first is the most supportive way of embedding it in school culture, and Wilde et al. (2019) discussed how misperceptions and a lack of genuine buy-in from the whole staff body can be a significant obstacle to implementing mindfulness in schools. This is in parallel with participant reports that staff bodies experiencing MBP courses/tasters was a large facilitator in implementation.

Participants were passionate about MBPs, which caused them to feel concerned about the potential for over-claiming for mindfulness interventions for students or rushing into MBP implementation by using teachers who were not properly trained. Likewise, commentators have also advised teachers to 'avoid being too messianic about mindfulness' and take a 'slow and steady' approach to embedding it in schools (Burnett 2015: p. 45-6). It is argued that caution is needed in a field where the evidence base is still emerging and contains many unknowns. Wilde et al. (2019) reported that staff involved in the implementation of MBPs in school were equally worried about unqualified staff delivering interventions and their ability to deal with students who might have a 'negative reaction' to mindfulness. Recent research in the field of adult MBPs has also started to recognise that mindfulness teachers need to be experienced and trained well enough to recognise trauma and other contra-indications to mindfulness meditation (Britton 2016; Treleaven 2018). This indicates that those involved in the delivery of MBPs to young people should strive to minimise harm by presenting realistic assessments of what mindfulness can do for participants and ensuring that welltrained facilitators are in place.

Other studies which have investigated the implementation of school-based MBPs support additional findings in this study. Wilde et al. (2019) noted that one major challenge is that early implementation is often spearheaded by a 'champion', whose energy and enthusiasm for mindfulness drives implementation, and this has also been found in other contexts, such as introducing MBCT into the UK health system (Crane and Kuyken 2013). In schools, this means that staff turnover can sometimes lead to the loss of MBP provision, if it has not been embedded, and several participants in this study were concerned that this would happen in their organisation. Desmond and Hanich (2010) additionally outlined problems regarding class-scheduling in setting up sessions, while Joyce et al. (2010) reported that staff delivering MBPs felt that lack of time amid 'multiple curriculum commitments' was the biggest barrier to implementation. Likewise, the current findings point to difficulties in finding curriculum time for MBPs in an already overloaded timetable, yet also note how crucial collegiate support is as a facilitator and how positive student feedback sustains and motivates these school staff to keep seeking ways to implement mindfulness in their schools.

To ensure integrated implementation within the school, participants spoke of the importance of offering mindfulness sessions and courses to senior leaders and coworkers first, in order to influence decision-making or to create a sub-group of practitioners in the school who could support each other. Wilde et al. stated that the delivery of MBPs to students is more effective when "offered as a regular and constant presence alongside opportunities for staff to experience mindfulness" (p. 11) so an initial focus on mindfulness at an institutional level seems be a factor in successful implementation. Additionally, participants were concerned that the current enthusiasm for mindfulness among some schools or teachers may not be tempered with solid teacher training in how to deliver mindfulness, and this has been raised as a concern by other school-teachers whose schools deliver MBPs (Wilde et al. 2019). RuijgrokLupton et al. (2018) showed that there is a correlation between the more time a mindfulness teacher spends in training and higher gains for adult participants in terms of well-being and reductions in stress, so the same may be true for school staff who deliver MBPs. However, this discussion would benefit from further research investigating what impact the school staff's level of training and MBP teaching competency has on student outcomes.

There are several other areas of possible future research on this topic. Firstly, qualitative findings from the study could be triangulated with interviews with 'key informants', such as students and colleagues, or with other research such as classroom observations and behaviour or progress records for students, in order to assess any impact of claims about improved interpersonal relationships and teacher efficacy. Additionally, the increases in staff pro-social dispositions could be further researched using third person 
cognitive behavioural measures (e.g. computer-assisted tests), as Roeser et al. (2013) suggested. Finally, more quantitative and qualitative research with schools that are successfully embedding mindfulness could be carried out, for example, by investigating what provision was offered to staff, or investigating other organisational supports as part of the journey towards wider implementation.

Qualitative research is concerned with generating insight and understanding into phenomena, rather than producing generalisable statements about the subject under study. As a result, findings from this small sample of eight cannot represent the experiences of all school staff delivering MBPs. However, as all participants shared similar experiences (such as increases in self-compassion or better relationships with students), it may be possible to extrapolate some tentative meaning; and the findings do fit with emerging quantitative evidence on how MBPs impact on school staff, and in turn, their students.

Another limitation may be connected to the researchers' own context; the first author had spent several years implementing MBPs in a school as well as, on several occasions, working with MiSP. There are limitations to a researcher having such an 'emic' perspective, as while there could be a high degree of empathy and rapport with participants during data collection, there was still a draw towards supporting and promoting the work of MBPs, which an 'etic' researcher may not have had. The lead author aimed to mitigate this by keeping a reflective diary throughout the study. When potential bias was identified through reflection, she created memos and shared them with the second author, especially during the later stages of analysis when the theme framework was being drawn up and data was being triangulated. Member checks were also carried out with participants in an attempt to test the validity of interpretation.

Author Contributions KRN: Led the study design, thematic analysis, and writing of the article. GMG: Contributed to the design and writing of the study, and triangulated the thematic analysis.

\section{Compliance with Ethical Standards}

Conflict of Interest The authors declare that they have no conflict of interest.

Ethical Approval This study was approved by Bangor University Ethics Committee and is therefore in accordance with the ethical standards laid down in the 1964 Declaration of Helsinki. All participants gave informed consent prior to their inclusion in the study.

Publisher's note Springer Nature remains neutral with regard to jurisdictional claims in published maps and institutional affiliations.

Open Access This article is licensed under a Creative Commons Attribution 4.0 International License, which permits use, sharing, adaptation, distribution and reproduction in any medium or format, as long as you give appropriate credit to the original author(s) and the source, provide a link to the Creative Commons license, and indicate if changes were made. The images or other third party material in this article are included in the article's Creative Commons license, unless indicated otherwise in a credit line to the material. If material is not included in the article's Creative Commons license and your intended use is not permitted by statutory regulation or exceeds the permitted use, you will need to obtain permission directly from the copyright holder. To view a copy of this license, visit http://creativecommons. org/licenses/by/4.0/.

\section{References}

Benn, R., Akiva, T., Arel, S., \& Roeser, R. W. (2012). Mindfulness training effects for parents and educators of children with special needs. Developmental Psychology, 48, 1476-1487.

Beshai, S., McAlpine, L., Weare, K., \& Kuyken, W. (2016). A nonrandomised feasibility trial assessing the efficacy of a mindfulness-based intervention for teachers to reduce stress and improve well-being. Mindfulness, 7, 198-208.

Braun, V., \& Clarke, V. (2006). Using thematic analysis in psychology. Qualitative Research in Psychology, 3, 77-101.

Braun, V. \& Clarke, V. (2013). Successful qualitative research: a practical guide for beginners. Sage.

Britton, W. B. (2016). Scientific literacy as a foundational competency for teachers of mindfulness-based interventions. In D. McCown, D.K. Reibel, M.S. Micozzi (Eds). Resources for teaching mindfulness: an international handbook (pp. 93-119). Springer.

Burke, C. A. (2010). Mindfulness-based approaches with children and adolescents: A preliminary review of current research in an emergent field. Journal of Child and Family Studies, 19, $133-144$.

Burnett, R. (2009). Mindfulness in Schools. Learning lessons from the adults-Secular and Buddhist Report. MiSP. www.mindfulnet. org/Mindfulness_in_Schools_Burnett_2009.pdf.

Burnett, R. (2015). Teaching mindfulness to captive teens in the classroom. In C. Willard, A. Saltzman (Eds) Teaching mindfulness skills to kids and teens (pp. 42-53). The Guilford Press.

Chambers, R., Gullone, E., \& Allen, N. B. (2009). Mindful emotion regulation: an integrative review. Clinical Psychology Review, $29,560-572$.

Chang, M.-L. (2009). An appraisal perspective of teacher burnout: examining the emotional work of teachers. Educational Psychology Review, 21, 193-218.

Crane, R. S., Brewer, J., Feldman, C., Kabat-Zinn, J., Santorelli, S., Williams, J. M. G., \& Kuyken, W. (2017). What defines mindfulness-based programs? The warp and the weft. Psychological Medicine, 47, 990-999.

Crane, R. S., \& Kuyken, W. (2013). The implementation of mindfulness-based cognitive therapy: learning from the UK health service experience. Mindfulness, 4, 246-254.

Davidson, R. J., Dunne, J., Eccles, J. S., Engle, A., Greenberg, M., Jennings, P., Jha, A., Jinpa, T., Lantieri, L., Meyer, D., Roeser, R. W., \& Vago, D. (2012). Contemplative practices and mental training: prospects for American education. Child Development. Perspectives, 6, 146-153.

Desmond, C.T., \& Hanich, L. (2010). The effects of mindful awareness teaching practices on the executive functions of students in an urban, low income middle school. Wellness Works in Schools. http://www.wellnessworksinschools.com/uploads/1/3/9/2/ 13927398/the_effectiveness_of_mindful_awareness_teaching_ practices_on_the_executive_function_behaviors_desmond_ millersville_1_.pdf.

Dettmers, J., Deci, N., Baeriswyl, S., Berset, M., \& Krause, A. (2016). Self-endangering work behavior. In M. Wiencke, M. Cacace, S. 
Fischer (Eds). Healthy at work: interdisciplinary perspectives (pp. 37-51). Springer International Publishing.

Dimidjian, S., \& Segal, Z. V. (2015). Prospects for a clinical science of mindfulness-based intervention. American Psychologist, 70, 593-620.

Elliott, R., Fischer, C. T., \& Rennie, D. L. (1999). Evolving guidelines for publication of qualitative research studies in psychology and related fields. British Journal of Clinical Psychology, 38, 215-229.

Emerson, L. M., Leyland, A., Hudson, K., Rowse, G., Hanley, P., \& Hugh-Jones, S. (2017). Teaching mindfulness to teachers: a systematic review and narrative synthesis. Mindfulness, 5, 1136-1149.

Feldman, G., Greeson, J., \& Senville, J. (2010). Differential effects of mindful breathing, progressive muscle relaxation, and lovingkindness meditation on decentering and negative reactions to repetitive thoughts. Behaviour Research and Therapy, 48, $1002-1011$.

Felver, J. C., \& Jennings, P. A. (2016). Applications of mindfulnessbased interventions in school settings: an introduction. Mindfulness, 7, 1-4.

Flook, L., Goldberg, S. B., Pinger, L., Bonus, K., \& Davidson, R. J. (2013). Mindfulness for teachers: a pilot study to assess effects on stress, burnout, and teaching efficacy. Mind Brain and Education, 7, 182-195.

Frank, J. L., Reibel, D., Broderick, P., Cantrell, T., \& Metz, S. (2015). The effectiveness of mindfulness-based stress reduction on educator stress and well-being: results from a pilot study. Mindfulness, 6, 208-216.

Gold, E., Smith, A., Hopper, I., Herne, D., Tansey, G., \& Hulland, C. (2010). Mindfulness-based stress reduction (MBSR) for primary school teachers. Journal of Child and Family Studies, 19, 184-189.

Good, D. J., Lyddy, C. J., Glomb, T. M., Bono, J. E., Brown, K. W., Duffy, M. K., Baer, R. A., Brewer, J. A., \& Lazar, S. W. (2016). Contemplating mindfulness at work: An integrative review. Journal of Management, 42, 114-142.

Hawkins, K. (2017). Mindful teacher, mindful school: Improving wellbeing in teaching \& learning. Sage.

Himelstein, S. (2015). Mindfulness-based substance abuse treatment with probation-involved youth. In C. Willard \& A. Saltzman (Eds). Teaching mindfulness skills to kids and teens (pp. 121-136). The Guilford Press.

Hwang, Y.-S., Bartlett, B., Greben, M., \& Hand, M. (2017). A systematic review of mindfulness interventions for in-service teachers: a tool to enhance teacher wellbeing and performance. Teaching and Teacher Education, 64, 26-42.

Jennings, P.A. (2015). Mindfulness for teachers: simple skills for peace and productivity in the classroom. W.W. Norton.

Jennings, P. A. (2016). Mindfulness-based programs and the American public school system: recommendations for best practices to ensure secularity. Mindfulness, 7, 176-178.

Joyce, A., Etty-Leal, J., Zazryn, T., Hamilton, A., \& Hassed, C. (2010). Exploring a mindfulness meditation program on the mental health of upper primary children: a pilot study. Advances in School Mental Health Promotion, 3, 17-25.

Kabat-Zinn, J. (1996). Full catastrophe living: how to cope with stress, pain and illness using mindfulness meditation. Piatkus.

Kaiser-Greenland, S. (2015). Foreword. In C. Willard, A. Saltzman (Eds). Teaching mindfulness skills to kids and teens (pp. xi-xv). The Guilford Press.

Kemeny, M. E., Foltz, C., Cullen, M., Jennings, P., Gillath, O., Wallace, B. A., \& Ekman, P. (2012). Contemplative/emotion training reduces negative emotional behavior and promotes prosocial responses. Emotion, 12, 338-350.

Kuyken, W., Weare, K., Ukoumunne, O. C., Vicary, R., Motton, N., Burnett, R., \& Huppert, F. (2013). Effectiveness of the Mindfulness in Schools Programme: non-randomised controlled feasibility study. The British Journal of Psychiatry, 203, 126-131.
Levitt, H. M., Bamberg, M., Creswell, J. W., Frost, D. M., Josselson, R., \& Suárez-Orozco, C. (2018). Journal article reporting standards for qualitative primary, qualitative meta-analytic, and mixed methods research in psychology: the APA Publications and Communications Board task force report. American Psychologist, 73, 26-46.

Maslach, C., Jackson, S., \& Leiter, M. (2010). Maslach burnout inventory manual. 3rd edition USA: Mind Garden, Inc.

McCown, D., Reibel, D., \& Micozzi, M. (2011) Teaching mindfulness: A practical guide for clinicians and educators. Springer.

McKeering, P., \& Hwang, Y.-S. (2019). A systematic review of mindfulness-based school interventions with early adolescents. Mindfulness, 10, 593-610.

Meiklejohn, J., Philips, C., Freedman, M. L., Griffin, M. L., Biegel, G., Roach, A., Frank, J., Burke, C., Pinger, L., Soloway, G., Isberg, R., Sibinga, E., Grossman, L., \& Saltzman, A. (2012). Integrating mindfulness training into K-12 education: fostering the resilience of teachers and students. Mindfulness, 3, 291-307.

Mindfulness All-Party Parliamentary Group (MAPPG) (2015). Mindful nation $U K$. The Mindfulness Initiative. http://www. themindfulnessinitiative.org.uk/publications/mindful-nation-ukreport.

Mindfulness in Schools Project (MiSP) (2017). Teach.b requisites. https://mindfulnessinschools.org/courses/prerequisites/dotb/.

Montgomery, C., \& Rupp, A. A. (2005). A meta-analysis for exploring the diverse causes and effects of stress in teachers. Canadian Journal of Education, 28, 461-488.

Napoli, M. (2004). Mindfulness training for teachers: a pilot program. Complementary Health Practice Review, 9, 31-42.

Onken, L. S., Carroll, K. M., Shoham, V., Cuthbert, B. N., \& Riddle, M. (2014). Reenvisioning clinical science: unifying the discipline to improve the public health. Clinical Psychological Science, 2, 22-34.

Roeser, R. W., Skinner, E., Beers, J., \& Jennings, P. A. (2012). Mindfulness training and teacher's professional development: an emerging area of research and practice. Child Development Perspectives, 6, 167-173.

Roeser, R. W., Schonert-Reichl, K. A., Jha, A., Cullen, M., Wallace, L., Wilensky, R., Oberle, E., Thomson, K., Taylor, C., \& Harrison, J. (2013). Mindfulness training and reductions in teacher stress and burnout: results from two randomized, waitlist-control field trials. Journal of Educational Psychology, 105, 787-804.

Ruijgrok-Lupton, P. E., Crane, R. S., \& Dorjee, D. (2018). Impact of mindfulness-based teacher training on MBSR participant wellbeing outcomes and course satisfaction. Mindfulness, 9, 117-128.

Rupprecht, S., Paulus, P., \& Walach, H. (2017). Mind the teachers! The impact of mindfulness training on self-regulation and classroom performance in a sample of German school teachers. European Journal of Educational Research, 6, 565-581.

Segal, Z. V., Williams, J. M. G., \& Teasdale, J. D. (2013). Mindfulness based cognitive therapy for depression (2nd ed.). The Guilford Press.

Shapiro, S. L., Carlson, L. E., Astin, J. A., \& Freedman, B. (2006). Mechanisms of mindfulness. Journal of Clinical Psychology, 62, 373-386.

Taylor, C., Harrison, J., Haimovitz, K., Oberle, E., Thompson, K., Schonert-Reichl, K., \& Roeser, R. W. (2016). Examining ways that a mindfulness-based intervention reduces stress in public school teachers: a mixed-methods study. Mindfulness, 7, 115-129.

Treleaven, D. (2018) Trauma-sensitive mindfulness: practices for safe and transformative healing. W.W. Norton \& Company.

Weare, K. (2013). Developing mindfulness with children and young people: a review of the evidence and policy context. Journal of Children's Services, 8, 141-153.

Weare, K. (2014). Evidence for mindfulness: impacts on the wellbeing and performance of school staff. MiSP. http://mindfulnessinschools. 
org/wp-content/uploads/2014/10/Evidence-for-Mindfulness-Impa ct-on-school-staff.pdf.

Wilde, S., Sonley, A., Crane, C., Ford, T., Raja, A., Robson, J., Taylor, L., \& Kuyken, W. (2019). Mindfulness training in UK secondary schools: a multiple case study approach to identification of cornerstones of implementation. Mindfulness, 10, 376-389.

Willard, C. (2015). Introduction: towards a model of teaching and learning mindfulness. In C. Willard, A. Saltzman (Eds). Teaching mindfulness skills to kids and teens (pp. 1-15). The Guilford Press.

Zenner, C., Herrnleben-Kurz, S., \& Walach, H. (2014). Mindfulnessbased interventions in schools-a systematic review and metaanalysis. Frontiers in Psychology, 5, 1-20.

Zoogman, S., Goldberg, S. B., Hoyt, W. T., \& Miller, L. (2014). Mindfulness interventions with youth: a meta-analysis. Mindfulness, 6, 290-302. 